BJHS: Themes 3:1-14, 2018. C British Society for the History of Science 2018. This is an Open Access article, distributed under the terms of the Creative Commons Attribution licence (http:// creativecommons.org/licenses/by/4.0/), which permits unrestricted reuse, distribution, and reproduction in any medium, provided the original work is properly cited.

doi:10.1017/bjt.2018.8

\title{
Worlds of science for children and young people, 1830-1991
}

\author{
ISABEL ZILHÃO* AND KRISTIAN H. NIELSEN*"
}

\begin{abstract}
Science for children and young people is an important, yet often neglected, subject in the historiography of science. It has gained attention due to the growing interest in science popularization. Like popular science, science for children and young people is a historical topic rich in fascinating stories about the ways in which scientific knowledge travels through society and culture. Although children and young people certainly belong to wider audiences for science outside the realm of specialized science, we have come to believe that studying science for children and young people allows us to probe even deeper into the ways in which science interacts with people's lives, their social relations and their hopes for the future. Children and young people since the Enlightenment have come to occupy a special role in Western society, and ideas about humankind, culture, learning, development and science have all been associated with childhood. When adults have presented scientific knowledge to children, they have not only built ideas (often ideals) about social order and proper upbringing into their materials, but also reflected upon questions about science in relation to children's capacity for acquiring new knowledge. We argue that children and young people historically and culturally constitute an important 'other' for science, and the historiography of science will benefit from taking on the topic of science for children and young people in this light.
\end{abstract}

[F]ollowing the optimistic illumination of the Enlightenment children have become our principal concern, we have become their protectors and nurturers and they have become our primary love objects, our human capital and our future. ${ }^{1}$

As children, and by way of children, we have, through modernity, dreamt of futures, and in so doing we have both justified and sought justification for modernity's expansionist urges in postDarwinian conflation of growth and progress. ${ }^{2}$

* Centro de História das Ciências e Tecnologia (CIUHCT), University of Lisbon, 1749-016 Lisbon, Portugal. Email: isabel.zilhao@gmail.com.

* Centre for Science Studies, Aarhus University, 8000 Aarhus C, Denmark. Email: khn@css.au.dk.

We would like to thank all the contributors to the two sessions on science for children and young people held at the Sixth International Conference of the European Society for the History of Science held in Lisbon, 4-6 September 2014. Your enthusiasm for the topic was always with us as we pulled this themed issue together. We would specifically like to thank the contributors to this issue for allowing all of us to continue work on such rich historical material. We are grateful to Jon Agar for facilitating, supporting and contributing to the editorial process, and to Trish Hatton for assisting us every step of the way.

1 Chris Jenks, Childhood, London: Routledge, 1996, p. 101.

2 Jenks, op. cit. (1), p. 106. 
We have sometimes come across historians of science who told us that science for children and young people is (but) a historical niche. Why, we wonder? We have all been children and experienced youth, so 'science for children and young people' is hardly marginal. Why do people feel that this theme is somehow peripheral to the history of science? Despite recent moves toward an enlarged view of the field, the idea that history of science proper deals with scientists and scientific practices is deep-seated. It is an integral part of our culture and thus must result from the ways in which our parents and teachers presented science to us when we were young. In addition, to find sources for historical studies of science for children and young people, we as historians must look outside the usual archives and publications, just as it is generally difficult to probe children's and young people's historical agency. Studies of childhood and youth are recent endeavours. The notion, however, that children and young people are the citizens of tomorrow has gained in importance since the eighteenth century. Furthermore, childhood and youth are not natural distinctions, but rather historically and culturally embedded categories. ${ }^{3}$

Science has penetrated childhood and youth to the extent that many of our ideas about what it means to be a child or a youth come from branches of science from psychiatry to anthropology and historical studies. ${ }^{4}$ Conversely, science, or rather science, technology and medicine, has played a crucial role in the rise of modernity and now forms part of the cultural background of growing up in the contemporary world. Therefore, dealing with science for children and young people from the perspective of the history of science, we believe, penetrates to the very heart of what sociologists of science refer to as the co-production of science and society. ${ }^{5}$ We hope that readers of this issue will agree with us that the topic offers new and refreshing insights into the ways in which science interacts with ways of living and ways of thinking about key issues in modern societies such as citizenship, education, personal development and knowledge. From years of studying science for children and young people in many historical contexts, we have found that it is a topic rich in fascinating stories and deep insights into the ways in which science has been communicated, performed and appropriated outside its own 'comfort zone'. Situated at the intersection between multiple historical specialities - science and childhood, of course, but also popular culture, education, gender, race/ethnicity and politics, to name the most obvious - science for children and young people as a topic for historical investigation has the potential to engage with diverse academic audiences. The transgressive nature of the topic, however, also poses historiographical challenges. How do we as historians of science approach the category of science for children? Should we see it as a

3 Philippe Ariès, Centuries of Childhood: A Social History of Family Life, New York: Alfred A. Knopf, 1962.

4 For treatments of childhood from different disciplinary perspectives see Jenks, op. cit. (1); David F. Lancy, The Anthropology of Childhood: Cherubs, Chattel, Changelings, Cambridge: Cambridge University Press, 2015; Barry Bogin, 'Childhood, adolescence, and longevity: a multilevel model of the evolution of reserve capacity in human life history', American Journal of Human Biology (2009) 21, pp. 567-577; David F. Bjorklund and Anthony D. Pellegrini, 'Child development and evolutionary psychology,' Child Development (2000) 71, pp. 1687-1708.

5 Sheila Jasanoff (ed.), States of Knowledge: The Co-Production of Science and the Social Order, London: Routledge, 2006. 
simplified version of science proper? If not, then how do we think about interactions between science as an adult affair and science for children? How have scientists, educationalists, politicians, children, youth and others at different times and places thought about and practised science for children and young people?

Such historiographical issues are similar in kind to those that historians of science in the past two decades or so have tackled in relation to popular science. In 1994, Roger Cooter and Stephen Pumfrey observed that historians of science had tended to shy away from popular science because of its diminished epistemological and social value. ${ }^{6}$ With reference to sociologists of science such as Richard Whitley and Bruno Latour, they stressed that science, popular science and culture interact in many different ways, suggesting that historians approach popular science in all its multiplicity and not simply as diffusion of scientific knowledge. Fifteen years later, Jonathan Topham echoed Cooter and Pumfrey in lamenting the marginalization of historical studies of popular science. Referencing James Secord's influential metaphor of 'knowledge in transit', Topham in a Focus section of Isis on popular science argued,

the practices of science popularization [are] firmly within the process of knowledge making, alongside such other communicative practices as talking and note taking in laboratory or field, writing research papers, defending research findings within learned societies and congresses, advising on government policy as an expert witness, and teaching students in classrooms and laboratories. ${ }^{7}$

Bernadette Bensaude-Vincent in the same Focus section broadened Topham's argument by saying that science develops in close historical relationship with its 'others', such as popular science or science for the public. ${ }^{8}$ 'The other' is a term borrowed from phenomenology used to denote the reflexive processes by which other human beings become constitutive for one's own identity. The constitutive other is different from yourself, yet also the same in the sense that the constitutive identity-shaping processes are symmetrical and often synchronous. Bensaude-Vincent uses the concept of the other more broadly to mean the reflexive, symmetrical constitution of social categories such as science by reference to other social categories. Understanding science in a historical context thus entails understanding how people have constituted the others of science such as the public. Children in this perspective become particularly interesting as they - perhaps even more so than the public - have played an important historical role as the other of science. Children, and more generally childhood, share a long and entangled history with science of which the articles in this themed issue, along with other important studies of science for children, can only claim to scratch the surface.

In our introduction to the 2018 issue of BJHS Themes, we first provide a brief overview of historical relations between science and children based primarily on state-of-the-

6 Roger Cooter and Stephen Pumfrey, 'Separate spheres and public places: reflections on the history of science popularization and science in popular culture', History of Science (1994) 32, pp. 237-267.

7 Jonathan R. Topham, 'Introduction: Focus: Historicizing “popular science”, Isis (2009) 100, pp. 301$318,311$.

8 Bernadette Bensaude-Vincent, 'A historical perspective on science and its "others"', Isis (2009) 100, pp. 359-368. 
art literature. We do not claim to be comprehensive; rather, we have indeed been thrilled to learn that the field of historical studies of science for children already has a long history itself and that the historiography of the topic holds many details and nuances, far too many to be covered here. A thorough scholarly review, we suspect, is much in demand. Then, we proceed to provide an overview of the papers, emphasizing the diversity of topics, approaches and conclusions. We consider temporal and geographical spread, different formats, adaptation to local cultural environments and gender issues.

\section{Historical relations between science and children}

As scientists established some of the first academies of science in Europe in the second half of the seventeenth century, early Enlightenment philosophers such as John Locke were arguing that children represented the ideal tabula rasa for learning. If advancing science hinged on the very possibility of learning, then the blank state of children's minds was one of the fundamental human conditions underlying science. Children in a sense were everything that science strove not to be, i.e. blank. Yet at the same time, Locke's philosophical construction of children as blank slates in regard to content and thus ready for the gradual development of rationality lent support to his empiricist epistemology for scientific knowledge. In fact, his speculations on children's capacities for moral and rational thinking appear at the very beginning of An Essay Concerning Human Understanding from 1689. Locke then proceeds to develop his ideas about the advancement of the sciences through organized experience. Like the sciences, children would gradually become moral and rational beings through focused education by their parents. Although Locke's ideas about education and epistemology were opposed to those put forward by other notable philosophers such as René Descartes who thought that rational capacities were indeed innate and that the sciences advanced through reasoned argument, Locke and Descartes fundamentally agreed that whatever characterized science had somehow to reflect whatever characterized children.

John Locke in the late 1690s worked as a tutor for the twelve-year-old son of Sir Francis and Lady Masham and tried his hand at communicating new scientific ideas to him. Locke produced a ten-thousand-word outline on his empiricist natural philosophy, never intended for publication, merely as a supplement to his lectures, but from the 1750 s onwards, the manuscript saw publication as a separate pamphlet. It also served as direct inspiration for one of the earliest science books for children, Tom Telescope's Newtonian System of Philosophy, adapted to the capacities of young gentlemen and ladies ... published in 1761 by (and usually attributed to) John Newbery. ${ }^{9}$ Newbury, unlike Locke, strove to make science playful by means of objects or toys already familiar to children. The book advertisement emphasized playfulness, describing it as a 'Philosophy of Tops and Balls'.

The book itself also portrayed science as being fully compatible with the teachings of the Bible and in accordance with the perceived moral virtues of the aristocracy. Science,

9 James A. Secord, 'Newton in the nursery: Tom Telescope and the philosophy of tops and balls, 17611838', History of Science (1985) 23, pp. 127-151. 
in other words, embodied close ties between rational, religious and social realms, and children's pursuit of science would only help to enforce such ties. Science was constitutive of the established order. With the market for children's literature burgeoning by the end of the eighteenth century, other authors adopted the 'instructive and amusing' genre. ${ }^{10}$ Tom Telescope's Newtonian System went through several editions, all of which were heavily modified to reflect dramatic developments in science and society. Thus, by the final edition of 1838, an exposition of more specialized scientific branches such as geology and magnetism had been included, and the original aristocratic setting replaced with a bourgeois middle-class one. ${ }^{11}$

By the mid-nineteenth century, as societies and journals for scientific specialisms and for public outreach appeared, science for children in Great Britain and elsewhere took on increasingly diverse forms. New practical lessons aimed at stimulating children's own engagement with their natural environment now supplemented books for schoolroom instruction in the sciences. Authors employed different literary forms such as dialogues, fables, object-centred conversations and even fairy tales to encourage children to see and understand their surrounding world through the lenses of the sciences. ${ }^{12}$ Vendors marketed new objects such as games and children's instruments to meet a demand for science-based leisure time in the domestic sphere. All of these developments shared with their eighteenth-century precedents the double ambition to present children with some modified version of scientific knowledge and to instil in them whatever the producers perceived to be proper social, moral, imaginary and rational competencies. Politeness and discipline, but also wonder at the marvels of nature and reasoned argument, were proper virtues for children. Exposure to science provided one of the means to obtain such parenting and educational goals. Resourceful parents and teachers valued science along with literature, music, sport and other activities as one of the foundations of good manners and culture. Science for children and young people thus reflected prevalent ideas about children and child rearing as much as ideas about science. ${ }^{13}$

With the spreading of democratic ideals and the emergence of mass culture, science for children and young people diversified even more while generally maintaining its instructional and educational bent. Greater attention to the child in scientific, educational and social spheres, as witnessed by, for example, child psychiatry, compulsory schooling and children's rights, also affected the ways in which authors and producers presented science to and deemed science appropriate for children. In the early twentieth-century United States, educational reformers affiliated with the nature study movement proposed

10 Aileen Fyfe, 'Young readers and the sciences', in Marina Frasca-Spada and Nick Jardine (eds.), Books and the Sciences in History, Cambridge: Cambridge University Press, 2000, pp. 276-290.

11 Secord, op. cit. (9), p. 144.

12 Melanie Keene, Science in Wonderland: The Scientific Fairy Tales of Victorian Britain, Oxford: Oxford University Press, 2015; Laurence Talairach-Vielmas, Fairy Tales, Natural History and Victorian Culture, New York: Palgrave, 2014.

13 See also the contributions to Laurence Talairach-Vielmas (ed.), Science in the Nursery: The Popularisation of Science in Britain and France, 1761-1901, Newcastle upon Tyne: Cambridge Scholars Publishing, 2011. 
curriculum reforms based on direct, hands-on experience with natural objects and field trips. ${ }^{14}$ The reformers believed that children's immediate experiences with nature should form the basis of all science teaching. They criticized existing science curricula for placing too much emphasis on logical deduction from fundamental theories and for trying to convey too many basic facts. Referring to progressive educational theory propounded by John Dewey, Francisco Ferrer, Maria Montessori and many others, they argued that children had an innate capacity for discovery and curiosity, but not logical thinking and rote learning. It followed that science teachers should provide children in elementary schools with sensory inputs stimulating their admiration for and amazement at nature and natural events, but also inspiring them to ask questions about what they saw and answer these questions in systematic ways. The exposure to nature in the wild, so to speak, would have the added benefit of allowing children who increasingly grew up in industrialized, urban environments to feel connected with nature.

The reformers of the nature study movement collaborated with museum curators to allow children to use the collections of natural-history museums in their investigations of natural specimens. In fact, many museums in the early decades of the twentieth century began to cater for larger numbers of children, and children seemed to flock to the museums - natural-history museums and museums of science and technology in particular. The Science Museum in London opened its Children's Gallery in 1931 partly in response to the increasing number of children who were visiting the museum's existing galleries intended for an adult audience and often were considered a nuisance by other visitors and museum staff. The main attraction of the gallery, at least from the point of view of its main curator, F.St.A. Hartley, was a number of historical-didactic dioramas presenting different modes of transport throughout the ages. Hartley argued that the dioramas would enable children 'to make comparisons between different methods of transport and to obtain a grasp of the general evolution of transport and its influence on the process of civilisation'. ${ }^{15}$ Thus the dioramas would serve the overall intention of the gallery, namely to show children what things such as means of transport meant in the daily lives of people. Placed in historical order, the dioramas presupposed, and tried to build, the discipline required in children to view the dioramas as planned and to absorb more or less implicit messages contained in them. In addition, the gallery adopted the hands-on approach that also inspired the nature study movement in the United States in a pulley block exhibition demonstrating the relative effectiveness of lifting the same weight by different arrangements of rope and pulley. Audience studies performed in the 1950s indicated that children, at least unaccompanied children, 'tended to flit from one thing to another, stopping to press buttons or turn handles and treating the Gallery more as an amusement arcade than as a source of scientific information'. ${ }^{16}$

14 Sally Gregory Kohlstedt, Teaching Children Science: Hands-On Nature Study in North America, 1890 1930, Chicago: The University of Chicago Press, 2010.

15 Quotation from Kristian H. Nielsen, “What things mean in our daily lives”: a history of museum curating and visiting in the Science Museum's Children's Gallery from c.1929 to 1969', British Journal for the History of Science (2014) 47, pp. 505-538, 514.

16 Nielsen, op. cit. (15), p. 529. 
Around mid-twentieth century, many different views on the relationship between science and children were available to those who wanted to produce and consume science content for children. Symmetrically, the way in which one understood children would affect the ways in which one understood science, and vice versa, and how best to connect those two categories. Some continued to see children as more or less blank slates in need of filling or as capable beings with innate capacities for learning in specific ways. Those who saw science as a collection of ready-made facts tended to opt for more didactic exposition, whereas those who believed that science was a way of thinking about the world or even as a way of being in the world would emphasize things like inquiry and problem-solving. Some were mostly concerned about the impact of science on society, whereas others wanted to present science as a rational and/or empirical mode of observing and explaining. Science for children, then, had become a heterogeneous field with entangled ideas about science, children and society.

After the Second World War, many industrialized countries began allocating public funds to scientific research and technological innovation. Investments in science and technology were essential for security and socio-economic growth. Because of the additional public money flowing into universities and research institutions and the increased significance attached to science and technology, many people addressed the lack of trained scientists and engineers. Where does one start looking for one's future scientists and engineers? Children, of course. In the United States and in other countries around the world, scientists, educationalists, corporate managers, politicians and others were looking for ways in which to attract children from an early age to science and engineering. The aim of making science appeal more to children resulted in initiatives such as talent searches, science clubs, science fairs, science centres, home labs, curriculum reforms and much more. ${ }^{17}$

Such initiatives are hard to characterize in a few words, yet observers have pointed out that one of the results has been an unintended alignment between science and children. ${ }^{18}$ Science is seen as 'childish' in the sense that it can be done by children, and children are understood as 'proto-scientific' because they by nature are curious and explorative. In other words, science defines children, as they are often, but not always, expected to behave like 'little scientists' and at an early age to prepare for scientific or engineering careers. ${ }^{19}$ Likewise, children define science as science often, but certainly not always, is believed to involve curiosity-driven exploration of the natural world.

The co-production of categories like science and children, we note, involves society in many ways. Since the Enlightenment, science for children and young people has served as more than a means to rational thinking and individual emancipation. Science allowed

17 Sevan G. Terzian, Science Education and Citizenship: Fairs, Clubs and Talent Searches for American Youth, 1918-1958, New York: Palgrave Macmillan, 2013; Rebecca Onion, Innocent Experiments: Childhood and the Culture of Popular Science in the United States, Chapel Hill: The University of North Carolina Press, 2016; John L. Rudolph, Scientists in the Classroom: The Cold War Reconstruction of American Science Education, New York: Palgrave, 2002.

18 Gertraud Koch, Estrid Sørensen and Les Levidow, 'Childish science: editorial introduction', Science as Culture (2011) 20, p. 421-431.

19 Onion, op. cit. (17), p. 165. 
children to see order and meaning in nature and society, and adults always saw science as a supplement to religious or liberal upbringing that would improve children's compliance and sense of duty. Science provided discipline and a work ethic. Learning about scientific developments, parents and instructors could help children take in the idea that they live within a grander scheme of things, a logical plan. For that reason, when they grow up, they comply more easily to a master plan. By way of this, there is an intimate relationship between science education and citizenship.

What we hope to have achieved by now is to have provided the reader with a few, but certainly not all, of the important themes of the historiography of science for children and young people. We have indicated that many important studies are out there already, but we have mentioned only a few. We have concluded that a philosophically nuanced and historically sensitive approach to the topic is the best way to go forward. Existing studies of science for children have tended to focus on larger countries such as the United States, Great Britain and France. We specifically would like to encourage historians of science with a special interest in how science has been presented to children and how this has affected the ways in which we think about both science and children to broaden their geographical and temporal scales. Our collection of papers results from two sessions organized by one of the authors (Zilhão) at the 6th International Conference of the European Society for the History of Science held in Lisbon, 4-6 September 2014. In what follows, we will provide a brief overview of the papers by looking at their geographical, temporal and topical diversity.

\section{Science for children and young people in different regions and periods}

We are painfully aware that the previous sections on historical relations between science and children and young people have a narrow outlook. One of the things that we like best about the articles collected in this BJHS Themes issue is that they describe people, events and topics that so far have received scant historical attention and thus are less well understood. Attempts at mobilizing science for educational and national purposes in nineteenth- and early twentieth-century Portugal nicely illustrate this. Gomes details how educational reformers sought to incorporate science teaching into Portuguese secondary schools from 1836 to 1933 to develop the rational and critical competencies required for pupils to become autonomous citizens and to support their individual process of personal formation. ${ }^{20}$ Zilhão finds that Prego's popular novels published in the early twentieth century also aimed to build children's moral and rational capacities. Educational reforms and Prego's novels about rural life shared the notion that scientific knowledge would be constitutive to building Portugal's future. ${ }^{21}$

In Gomes's case, the establishment of the First Portuguese Republic in 1910, despite political turmoil, gave rise to new hopes concerning curriculum reforms that would apply

20 Inês Gomes, 'Observation versus experimentation in natural-history teaching in Portuguese secondary schools: educational laws from 1836 to 1933 ', this issue.

21 Isabel Zilhão, 'Taking science to the countryside: fictionalizing the country through novels for young people in early twentieth-century Portugal', this issue. 
progressivist ideas about inquiry-based education and thus place more emphasis on pupils' own experimentation in school laboratories. Still, except for the introduction of new teaching aids such as microscopes and dissecting tools, traditional teaching methods based on classification and on what Gomes calls the historical-naturalistic approach remained pervasive. She cites institutional inertia, financial problems and political instability as the reasons why reforms were not implemented. Consequently, many pupils in Portuguese secondary schools were exposed to a curriculum centred on traditional biological classification methods where the handling of collection specimens was common. This, in turn, could be one of the reasons why Portugal today has what Gomes refers to as 'an outstanding scientific heritage, fortunately preserved by museums'. ${ }^{22}$

Zilhão, in a similar vein, notes that Prego, despite the liberal and reformist ideas propounded by his novels, remained conservative at heart. The protagonists of Prego's stories all came to value new knowledge as a means of progress in agriculture. The explicit message was that agricultural science and technology would have a positive impact on farming in Portugal. Implementing new knowledge and new techniques required new rural identities. Farmers and farm workers had to adapt to continual vocational training, and children and young people had to be able to demonstrate initiative and problemsolving capacities. This would have the added effect of making the public image of living in the countryside more consistent with modern values such as progress and liberal economy. Yet, at the same time, Prego tried to balance his liberal, progressive messages with advocacy of the status quo when it came to redistribution of wealth and power in Portuguese society. As in Gomes's case, actual reform turned out to be difficult. Presenting scientific and technical issues to children and young people in novel ways could have been the compromise that Portuguese educational reformers and science popularizers chose in order to balance new ideas with the existing order. ${ }^{23}$

As scientific knowledge and educational ideas circulate from one context to another they become amendable to change and translation. They simply mean different things to different people. Yet some forms of knowledge and some ideas have remained remarkably stable as they have moved across geographical and temporal boundaries. They seem to aspire to a kind of universality, which in part could be due to the ways in which, and the extent to which, they circulated. Progressive education is a case in point. Many articles in our collection deal with the remarkable circulation of some of the basic ideas of progressive education, most notably the emphasis on inquiry-based, experiential learning. The Book of Knowledge studied by Oliveira, for example, claimed to teach testing, and not handed-down knowledge, as the true authority in science. In reality, however, the book always referred to scientists and scientific institutions as the proper sources of authoritative knowledge. The book appeared in many languages and thus helped to spread the idea of progressive education around the world, even though the book itself did not really practise what it taught. ${ }^{24}$ The same goes for the idea of

22 Gomes, op. cit. (20).

23 Zilhão, op. cit. (21).

24 Bernardo Jefferson de Oliveira, 'Science in The Children's Encyclopedia and its appropriation in the twentieth century in Latin America', this issue. 
'integrated science teaching' in Nielsen's paper, which shared many features with progressive education. Although UNESCO's programme in integrated science teaching made possible wide distribution of the basic ideas and practices propounded by UNESCO, the programme also allowed for a high degree of flexibility regarding the very meaning of integrated science teaching. It seems as if interpretive flexibility makes the wide circulation of ideas easier. ${ }^{25}$

\section{Ways of communicating science to children and young people}

Science, James Secord argued in his widely cited keynote address delivered at the fifth joint Three Societies Meeting in Halifax in 2004, is a form of communicative action. ${ }^{26}$ This is obviously true since science involves communication all the way through from observation to deliberation to publication. It could even be true in a more fundamental sense if one were to adopt an approach to communication in which communication does not mean transmission but rather is a self-referential process that constitutes meaning within the framework of a system. ${ }^{27}$ This would mean that science itself, as a system for making meaning in specific ways, becomes science through communication, and not the other way around, where communication is an event that takes place after the real science is completed. In this view, science is the totality of all communication that attributes meaning to the notion of science. Regardless of such systems-theoretical speculations, the historiographical advantages of looking at science as a form of communicative action, Secord notes, is that it allows us to resolve the apparent paradox between science's socio-historical situatedness and its global pervasiveness by looking at knowledge that travels from a few local settings to many others. Secord recommends that we attend to processes and practices of circulation of knowledge in addition to (maybe rather than) production and consumption of knowledge, and that we try to understand why some patterns of circulation are more durable than others and why some forms of knowledge travel 'lighter' than others.

Although the articles in this BJHS Themes issue do not claim to adhere systematically to Secord's recommendations, we do find that most authors exhibit the kind of historical sensitivity to processes and formats of communication, which is the core of the 'Secordian' historiography. Richard Somerset, for example, looks at the rise of a chronological narrative in nineteenth-century natural history. The genre of 'popular history of life', as he calls it, used palaeontological and stratigraphic evidence to offer a comprehensive story about major epochs in the chronology of the Earth and of life on Earth. Somerset argues that the popular genre, to become broadly popular, had to meet certain pedagogical or rhetorical demands such as a coherent plot, key actors and major events. As much as the geological record, the requirements of the popular genre helped preconfigure the scientific narrative. Telling the story of life to children and

25 Kristian H. Nielsen, 'Ideas, politics and practices of integrated science teaching in the global Cold War', this issue.

26 James A. Secord, 'Knowledge in transit', Isis (2004) 95, pp. 654-672.

27 Niklas Luhmann, Social Systems, Stanford, CA: Stanford University Press, 1995. 
young people was a good place to experiment with emergent naturalistic themes and narratives. $^{28}$

In a similar vein, Peter Bowler's article about the Meccano Magazine in the twentieth century deals with the entanglement between scientific genres for adults and children and young people respectively. Although Meccano Magazine was a magazine for boys, used to promote the Meccano toys, it also devoted editorial space to stories about science and technology (mostly technology). Its editor Ellison Hawks from 1922 to 1935 obviously liked to write about new scientific and technological developments (he also authored a few popular boys' books). As a result, Meccano Magazine in many ways resembled a regular popular-science magazine and probably many adults (mostly fathers?) read it. Its juvenile popular science stories for a while covered the entire market for popular science magazines. Interestingly, Bowler notes, fathers probably also read the Meccano Magazine, which made it a competitor of its adult counterparts. ${ }^{29}$ Bowler's observation is noteworthy not least because opportunistic reading of the writings for young people by less sophisticated adults usually passes unnoticed. The set of books on agriculture discussed by Zilhão is another case in point. ${ }^{30}$

\section{Cultural appropriation, citizenship and gender}

While most leisurely reading material appealed to, and sought to develop, children's faculties of imagination and reason, it also aimed to mould children's ideas about the world and their own future role as rational citizens. Indeed, all authors touch on science for citizenship and social responsibility. Chando Roy, for example, discusses the importance attached to scientific education in late nineteenth-century colonial Bengali society for overcoming both colonial discrimination and traditional injustice. He argues that although British rule over India was highly criticized, the local avant-garde nonetheless recognized that scientific knowledge would bring prosperity to India and prove invaluable in overthrowing firmly rooted prejudices, such as child marriage, folk knowledge and Indian mythology. In magazines about science intended for juvenile audiences, they tried to combine Western knowledge about the natural world, especially about plants and animals, with Indian views about the compassionate relation between humankind and nature. Mostly, however, they ended up replacing traditional Indian world views with the kind of scientific curiosity and rationality they thought would be more appropriate for the new Bengali middle class. In the end, however, the protagonists of Chando Roy's story failed to meet their aims because of insurmountable structural differences within Bengali society. Science for children and young people, in fact, deepened

28 Richard Somerset, 'Palaeontological pedagogues of the 1830s: the prehistory of the "history of life" genre', this issue.

29 Peter Bowler, 'Meccano Magazine: boys' toys and the popularization of science in early twentieth-century Britain', this issue.

30 Zilhão, op. cit. (21). 
rather than diminished the gap between the educated Bengali middle class and the 'others' that it sought to enlighten. ${ }^{31}$

Contrast the Bengali juvenile magazines with the Meccano Magazine studied by Bowler and The Children's Encyclopedia in Oliveira's paper, both of which place science as the sole source of natural knowledge and portray nature in utilitarian terms, and then it becomes easy to compare science for children and young people across cultural settings. ${ }^{32}$ Even though the connection between science and the British colonies also featured in the Meccano Magazine, the perspective obviously was a different one. Bowler notes that Ellison Hawks, the editor of Meccano Magazine from the early 1920 s to 1935 , portrayed science and technology as means of expanding the British Empire. Whereas the Bengali avant-garde in Roy's paper had to strike a compromise between science as representative of the modern world and traditional Indian values, Hawks undauntedly promoted the relevance of science for national prosperity and extended colonization. In a similar vein, Oliveira finds that the representation of science remained virtually unchanged through numerous translations of The Children's Encyclopedia, yet the meanings that readers would attach to the articles would change. Oliveira's paper provides insights into the remarkable stability of science for children and young people, all the while noting that same words would have different connotations in different milieus.

The book collection on agriculture written by João Coelho da Mota Prego, discussed in the paper by Zilhão, was a tool for improving Portuguese young people's future. ${ }^{33}$ Zilhão discusses how science and technology as featured in Prego's books on agriculture served the purpose of re-educating the Portuguese rural inhabitant and reviving the country's agriculture-based economy. Zilhão particularly stresses that the book's representation of scientific and technological knowledge responded to social and economic problems in Portugal at the time, such as literacy or rural development. Interestingly, there are historical parallels between Zilhão's story and Nielsen's paper on the UNESCO Programme in Integrated Science Education that took off in 1969. UNESCO's programme, aimed at integrating science into primary-school curricula all around the world, specifically sought to improve literacy and development in less developed countries. ${ }^{34}$ The basic assumptions underlying the UNESCO programme were in many ways similar to Prego's liberal ideas.

Before we conclude our thematic exposition of the rich material included in this issue, we should note that gender is an implicit theme in some papers. Some authors, such as Bowler, observe traditional gender roles with the Meccano Magazine described as 'the best and brightest paper for boys', whereas others, such as Chando Roy and Zilhão, place more emphasis on female agency. The juvenile magazines for Bengali children in Chando Roy's paper targeted both boys and girls. In this respect, they challenged traditional views according to which girls were supposed to marry very early and expect

31 Gautam Chando Roy, 'Science for children in a colonial context: Bengali juvenile magazines, 18831923', this issue.

32 Oliveira, op. cit. (24); Bowler, op. cit. (29).

33 Zilhão, op. cit. (21).

34 Nielsen, op. cit. (25). 
nothing from their adulthood but becoming good wives. The magazines in a certain sense created an intellectual and emotional space shared by both genders, before marriage would prohibit free mixing of men and women. Girls were encouraged to write to the magazines to express their own opinions on topics, and the magazines featured several women authors. All the same, the attitude towards the female gender remained one of stigmatization: the magazines mostly portrayed girls as passive, respectful and obedient, and not given to enterprise. ${ }^{35}$ Unsurprisingly, given the magazine's explicit emphasis on boys, this is more or less the same gender bias that we can observe in the Meccano Magazine discussed by Bowler. ${ }^{36}$ Zilhão, however, finds that girls in Prego's turn-of-the-century stories about life in the Portuguese countryside had entrepreneurial qualities. Moreover, they were educated and often the protagonists and in Prego's novels were able to use science and technology to overthrow deeply rooted superstitions. ${ }^{37}$

\section{Science and children}

Science for children and young people in this issue is Janus-faced. ${ }^{38}$ On the one hand, obviously, the papers' historical narratives about authors, translators, educators, reformers and, unfortunately less so, children and youth all revolve around aspects of science. Science for children and young people belongs to popular science. As popular science, it deserves historical treatment as a cultural manifestation of science that tells us about prevalent ideas about science, society and their relationship. It is a special kind of popular science because it aims at connecting the citizens of tomorrow with science. Science for children and young people, in this respect, serves to build humans and literally shape the future by moulding the people that will inhabit it.

The other side of the Janus face has to do with childhood and youth. Just as science is a historically variable and socially situated category, so, needless to say, are childhood and youth. As the papers in this issue all demonstrate, we believe, stories about the role of science in childhood and youth provide fresh perspectives on historical notions about childhood and youth. Science has played and continues to play an important role in children's and young people's lives. As historians of science, well accustomed to science's multiplicity and heterogeneity, we have an obligation to contribute to the historiography of childhood and youth by addressing the position and function of science in the early and formation stages of people's lives. However, and this is the practical lesson we had learn from engaging with this topic for so long, there is a problem for historians who want to engage with the lives of children. As historian of childhood Hugh Cunningham noted long ago, historical writing about children often has more to do with adults than with children. '[I]t is easier', he wrote, 'to write with some confidence

35 Chando Roy, op. cit. (31).

36 Bowler, op. cit. (29).

37 Zilhão, op. cit. (21).

38 The Janus-face metaphor in relation to science comes from Bruno Latour, but we use it in a different way. Bruno Latour, Science in Action: How to Follow Scientists and Engineers through Society, Cambridge, MA: Harvard University Press, 1987, p. 7-13. 
about childhood than about children'. ${ }^{39}$ We also mentioned the difficulty of identifying children's historical agency at the beginning of our introduction. ${ }^{40}$ We readily acknowledge that this issue treats the topic of science for children and young people from the perspective of adults, and we strongly encourage other historians to find ways in which to make children and young people more active participants in the stories we tell about science.

A final challenge, of course, remains in bringing the two sides of the Janus face together. How do we connect the historiography of childhood and youth to that of science? In the beginning of our introduction, we proposed understanding childhood and youth as the other of science. Whatever people have thought about children reflects whatever they have thought about science, at least in some cases. We found evidence of this rather grand claim in early enlightenment philosophers such as John Locke and René Descartes, but clearly it is an idea that is in need of much more elaboration. In the course of what Swedish feminist Ellen Key in 1900 named 'the century of the child', childhood, youth and science surely have emerged as key social institutions and their relationships have begun to attract serious historical attention. ${ }^{41}$ History of science should have a crucial role to play in probing the symmetrical and synchronous co-production of science and children, and we encourage other historians of science to take on this important task.

39 Hugh Cunningham, Children and Childhood in Western Society since 1500, London: Longman, 1995, p. 3.

40 There is an ongoing critical debate about children's agency in cultural anthropology. See David F. Lancy, 'Unmasking children's agency', AnthropoChildren: Enthographic Perspectives in Children and Childhood (2012) 2, at http://popups.uliege.be/2034-8517/index.php?id=1253, accessed 4 February 2018. For a recent example of how children and young people can be identified more clearly as actors, not merely subjects of historical analysis, see Mona Gleason, 'Avoiding the agency trap: caveats for historians of children, youth, and education', History of Education (2016) 45, pp. 446-459.

41 Cunningham, op. cit. (39), p. 163. 